\title{
Percutaneous catheterisation of the radial artery in newborn babies using transillumination
}

\author{
R. G. PEARSE
}

From the Department of Paediatrics, Erasmus University and Academic Hospital, Sophia Children's Hospital and Neonatal Unit, Rotterdam, The Netherlands

SUMMARY A technique for inserting radial artery catheters percutaneously in newborn babies using transillumination is described. Catheterisation was successful in $69 \%$ of the 107 babies in whom it was attempted. In the last 30 attempts there was an $85 \%$ success rate with an average useful life of 100 hours. The average weight of these babies was $1405 \mathrm{~g}$, with a range of $620-4250 \mathrm{~g}$. The method has several advantages over previous methods.

A rapid, simple, and safe method of cannulating the radial artery percutaneously in newborn babies is described. Early results with this technique have been reported previously (Pearse, 1977).

\section{Apparatus}

A rubber oxygen funnel cut down to a diameter of $2 \mathrm{~cm}$ (Fig. 1) is attached to the end of a fibreoptic bundle, connected to a variable intensity, cold light source (American Cystoscope Makers Inc., ACMI 95A). This apparatus is also used for transilluminating the skull and for the rapid detection of pneumothoraces (Kuhns et al., 1975).

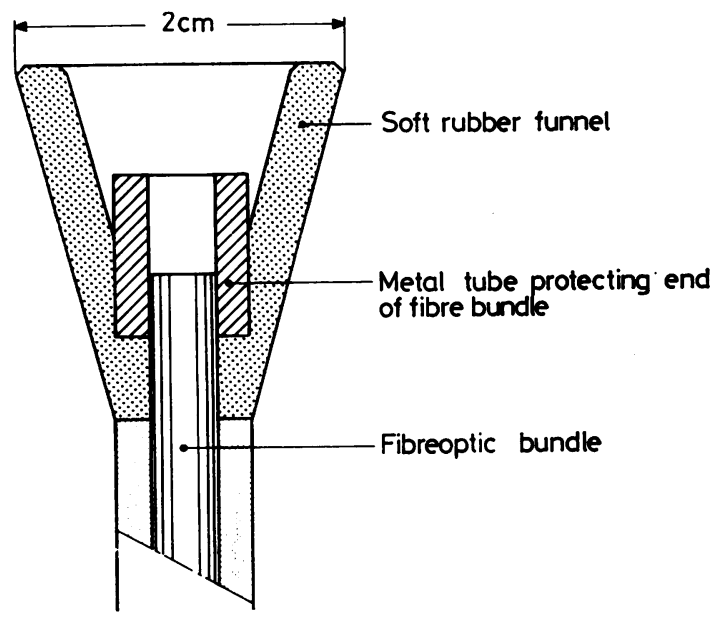

Fig. 1 Diagrammatic representation of the distal end of the fibreoptic bundle.

Received 16 December 1977
The catheter is an Abbocath 22G, made of soft Teflon mounted on the outside of a hollow metal stylet. The stylet is fixed to a clear plastic chamber which has a filter permeable only to air at the opposite end, so that blood is able to flow back up the stylet and into, but not out of, the chamber. After successful insertion, the catheter is attached to a piece of clear plastic extension tubing $7 \mathrm{~cm}$ long (volume $0.2 \mathrm{ml}$ ) with an inbuilt 3-way stopcock (Viggo 4041-0).

\section{Method}

The forearm of the baby is held, ventral surface uppermost, between the index and middle fingers of the operator's left hand (Fig. 2). The baby's hand is held slightly dorsiflexed by the operator's thumb (over-extension of the hand causes reduced flow

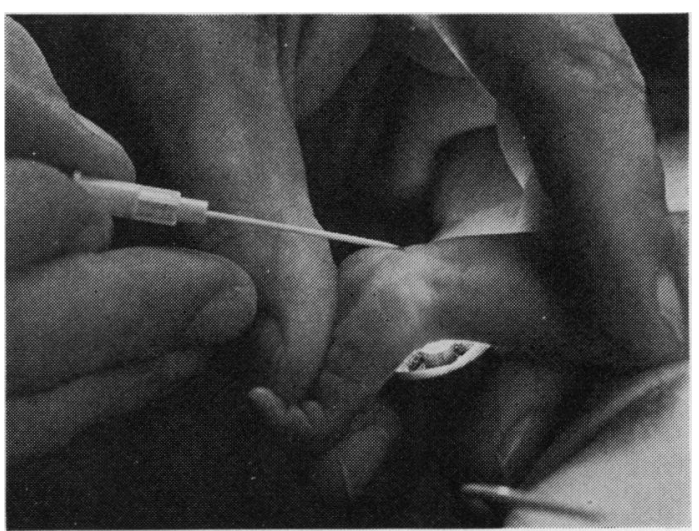

Fig. 2 Position of the operator's left hand, holding the baby's right arm and the transillumination funnel. 
through the radial artery and makes the procedure more difficult). The rubber funnel is held between the middle and ring fingers against the dorsal surface of the baby's wrist. From the ventral side it is possible to see the radial and ulnar arteries in the lower forearm and wrist, as dark lines against a bright, transilluminated, background (Fig. 3). It is not usually necessary to darken the room to see these quite clearly. The arteries may be differentiated from the veins in this region because the latter move with the skin, whereas the arteries are fixed.

After identifying the two arteries, the wrist is held firmly on the radial side and the blood squeezed out of the hand. If the colour returns rapidly to the hand while pressure is maintained over the radial artery it is safe to assume that the collateral circulation in the hand is sufficient (Allen, 1929) and that the catheterisation may proceed.

The wrist is cleaned with an iodine/alcohol solution and this is washed off with chlorhexidine in alcohol and allowed to dry. Holding the funnel beneath the wrist in the manner described, an Abbocath is advanced slowly, under direct vision, in the direction of the radial artery at an angle of about $20^{\circ}$ until blood can be seen in the clear plastic chamber. The Abbocath is then advanced a further half $\mathrm{mm}$ (to bring the tip of the Teflon catheter into the arterial lumen) and then, while advancing the Tefion catheter slightly with thumb and index finger, the stylet is slightly withdrawn using the middle finger against the palm. The Teflon catheter can now be pushed with ease up the artery and the stylet completely withdrawn, placing the index finger of the left hand over the radial artery, just proximal to the tip of the catheter, to prevent blood loss.

The catheter is now attached to the extension tubing, which has been previously filled with saline containing 5 units heparin $/ \mathrm{ml}$. Blood is allowed to run back into the plastic tubing and the system is checked for air bubbles. The catheter is flushed with the heparin solution and the tap turned off towards the patient. The catheter is fixed to the skin using a narrow piece of sticking plaster (approximately $3 \mathrm{~mm}$ wide) placed adhesive side uppermost under the catheter and then crossed over the catheter and stuck to the skin of the forearm to form a V-shape, with the point of entry of the catheter in the skin at the apex of the ' $V$ '. The entry point is sprayed with a plastic spray (for example Nobecutane). The arm is splinted and the hand fixed to the splint so that the fingers and thumb can be clearly seen (Fig. 4). Rubber stoppers (Braun, 23751) are attached to the side holes of the 3-way stopcock and samples are withdrawn by piercing these with a $23 \mathrm{G}$ needle attached to a $1 \mathrm{ml}$ syringe, preferably a glass one. All connections in the system are made by Luer locks to lessen the risk of accidental detachment and subsequent haemorrhage.

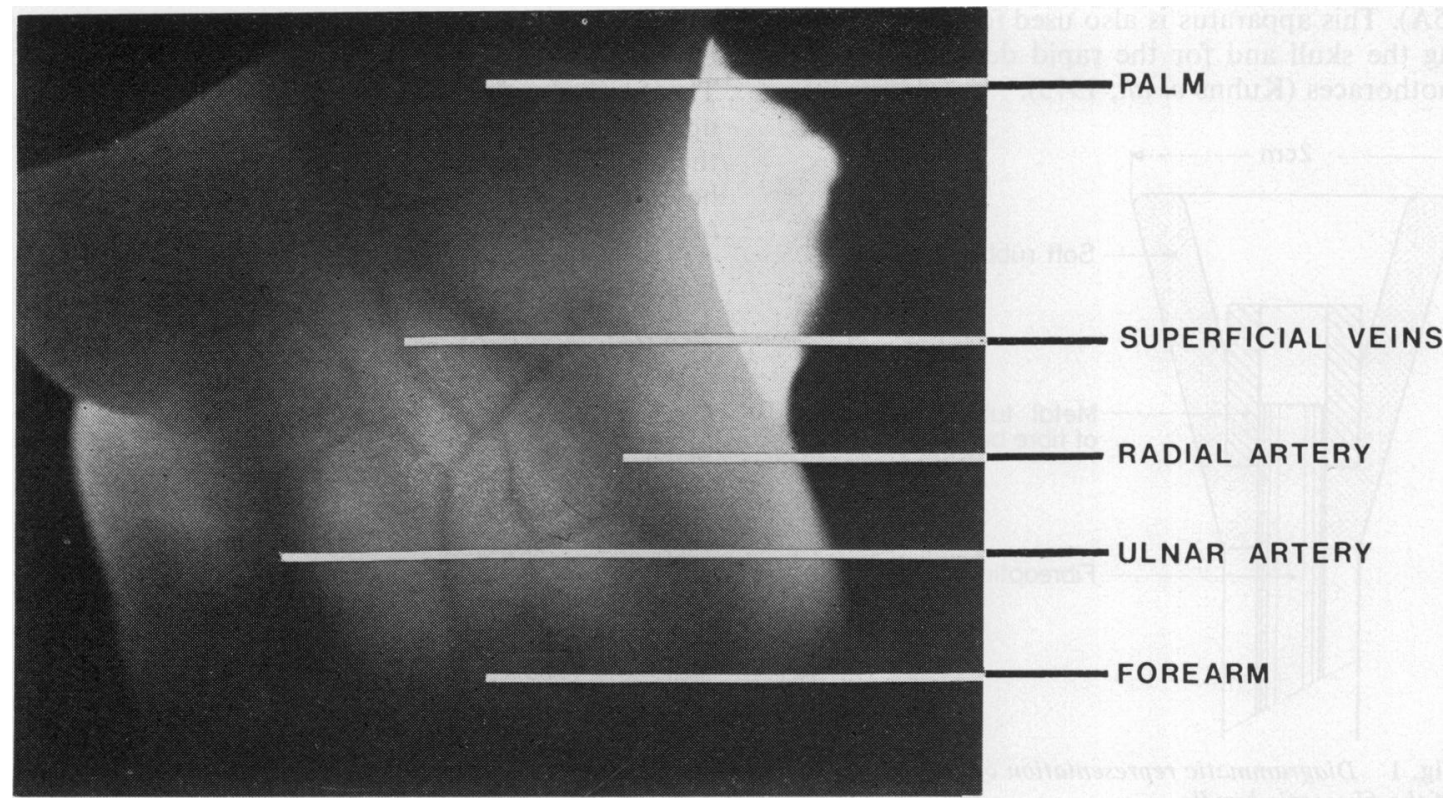

Fig. 3 Radial and ulnar arteries as seen by transillumination of the wrist. Their outline is blurred because they lie deep and the light is dispersed by the overlying tissues. 


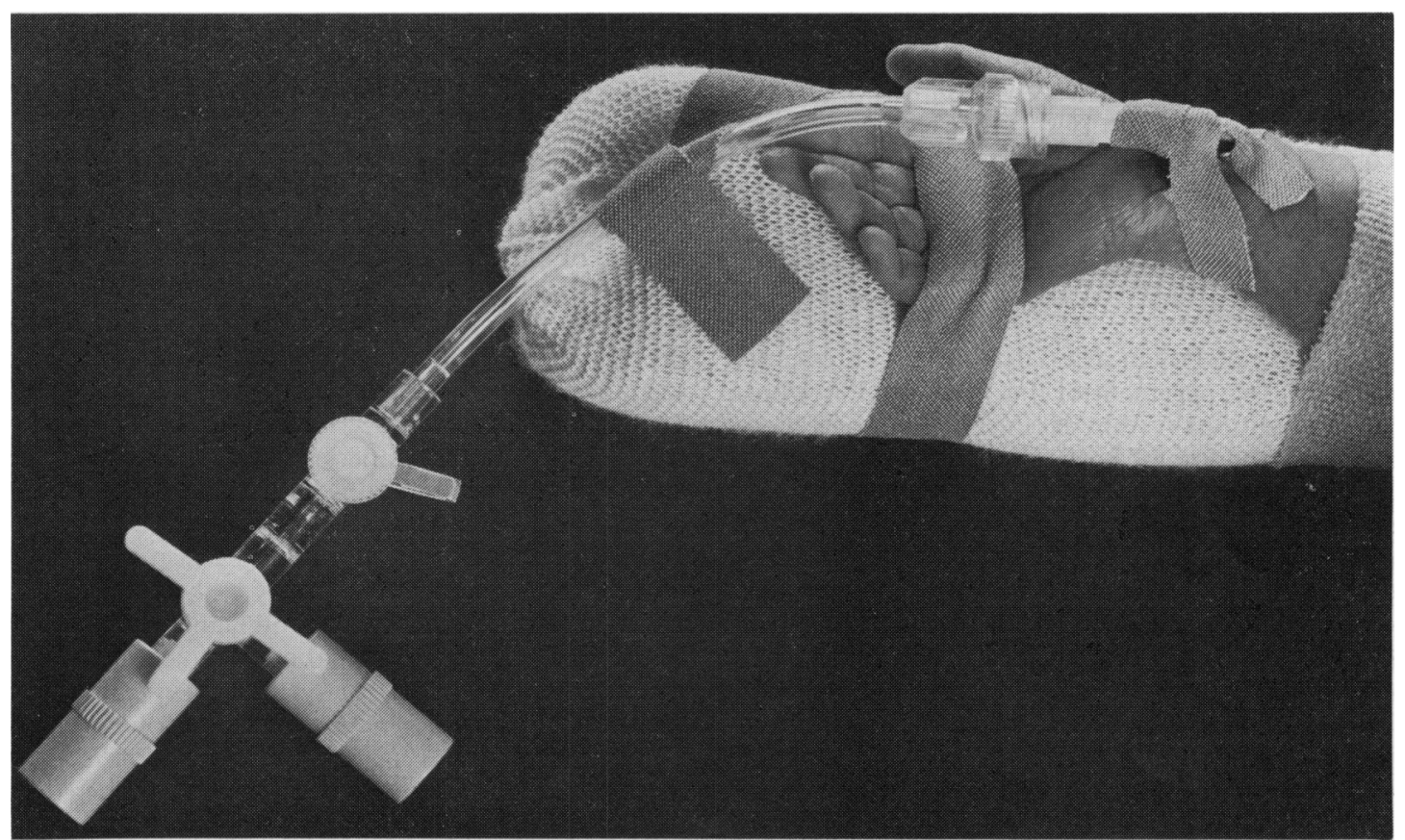

Fig. 4 Method of fixation of the catheter and of splinting the arm.

\section{Results}

Radial artery catheterisation was attempted in 107 babies. In $74(69 \%)$ of these it was successful, and their average weight was $1466 \mathrm{~g}$ (range 620 to $4250 \mathrm{~g}$ ). (There was an $85 \%$ success rate in the last 30 attempts as the five neonatologists become more adept at the technique. The average weight of these babies was $1405 \mathrm{~g}$.)

The catheters so placed had an average useful life of 70 hours, with a range of 10 to 240 hours. The majority $(69 \%)$ were removed because it was no longer possible to obtain a sample through them. Why this was so is not clear as it was generally still possible to obtain the typical arterial blanching pattern of the skin on flushing the catheter. Presumably this is because there is a clot just proximal to the catheter tip which acts as a ball valve, or because of arterial spasm. No catheter contained a clot when it was removed. In $7 \%$ of cases the catheter had to be removed because blood was leaking from around the catheter. In $18(24 \%)$ of cases the catheter was removed because it was no longer necessary, either because the condition of the baby had improved so it was no longer necessary to monitor blood gases (12 $(16 \%)$ babies) or because the baby had died (6 ( $8 \%$ babies).
All catheter tips were cultured after removal. In two cases Staphylococcus epidermidis was grown, but in neither baby was this associated with overt clinical disease. The remaining 72 cultures were sterile. A pustule developed on the ventral surface of the wrist of one baby 10 days after the removal of the catheter. It appeared from its location to be more probably related to an intravenous infusion, inserted some days after the removal of the catheter, and removed 3 days previously. Staphylococcus aureus (coagulase positive) was cultured from the lesion.

Complications have been slight. In 5 babies, ecchymoses developed in the skin of the anterior aspect of the forearm. These all occurred early in the series and may have been associated with overenthusiastic flushing of the catheter. In 2 babies, each with systolic blood pressure below $25 \mathrm{mmHg}$, the circulation in the hand gave cause for concern shortly after the catheter had been inserted, but within 2 minutes the circulation had improved spontaneously without the catheter being removed. One baby developed a white thumb 20 hours after insertion of the catheter. The catheter was removed and the circulation in the hand rapidly returned to normal. This was thought to be due to spasm caused by prolonged manipulation in an attempt to obtain a sample. 
Radial artery catheters have been in regular use in this unit since August 1976, and as yet, no long-term complications have been seen. Follow-up of these babies is planned, with particular reference to subsequent growth and function of the forearm and hand and to the return of the pulse in the radial artery.

\section{Discussion}

Monitoring of $\mathrm{Po}_{2}$ in arterial blood is an essential part of the management of the seriously ill newborn baby. Traditionally this has meant sampling blood from the abdominal aorta via an umbilical artery catheter, which has great disadvantages. It is becoming increasingly apparent that this procedure has a fairly high rate of complications, particularly with regard to infection and thromboembolism. Krauss et al. (1970) reported a contamination rate of $55 \%$ for umbilical arterial catheters. Thrombosis, with or without embolism, occurs in up to $95 \%$, regardless of the duration of catheterisation according to Neal et al. (1972). Most authors quote rates of between 8.8 and $59 \%(21 \%$ Cochran et al., 1968; 12\% Wigger et al., 1970; 8.8\% Egan and Eitzman, 1971 ; $23 \%$ Tooley, $1972 ; 59 \%$ Tyson et al., 1976). More unusual complications include paraplegia (Krishnamoorthy et al., 1976), intestinal perforation (Hoekstra et al., 1977), septic osteoarthritis (Knudsen and Petersen, 1977), false aortic aneurysm (Malloy and Nichols, 1977), and in the long term, hypertension (Plumer et al., 1976). The sample obtained by this route may also be a poor reflection of the blood going to the brain and retina because of right-to-left shunting through the ductus arteriosus (Roberton and Dahlenburg, 1969). Nor is it possible to insert an umbilical artery catheter after the first few days of life.

In the search for better sites from which to sample arterial blood, most authors have concentrated on the superficial temporal and radial arteries. Early experience with multiple puncture techniques in these arteries has been reported by Thomsen (1964), Bucci et al. (1966), Shaw (1968), and Wunderlich and Reynolds (1972). There is general agreement that haematoma formation at the puncture site is a common complication. While this is not a great problem in the case of the temporal artery, because a relatively long segment of the artery is available for puncture, the radial artery is available for puncture only over a short distance. Haematoma formation makes subsequent puncture considerably more difficult. A further argument against multiple puncture techniques is that the sample obtained is probably a poor indication of the situation pertaining before the procedure was begun, particularly if difficulty was experienced in obtaining the sample (Dangman et al., 1976).

Access to the temporal artery is moderately easy during ventilator therapy, but it is more difficult to obtain a meaningful sample while the baby is breathing spontaneously in an oxygen-enriched atmosphere. These problems are largely overcome by the use of indwelling catheters in the temporal artery (McGovern and Baker, 1968; Gauderer and Holgersen, 1974). However this requires a surgical cutdown procedure on the artery, with or without arterial section, and involves the child in much handling. Excellent results have been described by Au-Yeung et al. (1977) of percutaneous catheterisation of the temporal arteries but it is difficult in the first 24 hours of life because of scalp oedema.

A surgical cutdown procedure has also been used for the placement of radial artery catheters (Bartlett and Munster, 1968; Roberton and Dahlenburg, 1969; N. R. C. Roberton, personal communication, 1977) with its attendant risks of vessel loss and infection plus the harmful effects of prolonged handling on the baby. Percutaneous radial artery catheterisation avoids these problems. In a series of 20 patients reported by Adams and Rudolph (1975) only one failure occurred: however the mean weight of this group was $2.534 \mathrm{~g}$ and the smallest weighed $1418 \mathrm{~g}$. In the series of 72 neonates described by Todres et al. (1975), percutaneous cannulation was successful in $73 \%$ : the average weight of these babies was not given but the range was 1100 to $4000 \mathrm{~g}$. Neither article reported any major complications other than haematoma formation. If the right radial artery is catheterised, then the sample obtained is preductal and can be removed without disturbing the baby. If a Gairdner box (Warley and Gairdner, 1962) is being used to administer extra oxygen, then the sample can be withdrawn without altering the concentration of oxygen in the inspired air. Transillumination makes radial artery catheterisation a rapid and simple procedure even on the smallest babies, which in practised hands can be completed within two minutes, thus shortening the time taken while handling the baby and lessening the subsequent fall in arterial $\mathrm{PO}_{2}$.

No continuous infusion was used to keep these catheters open because it was felt inadvisable to use any fluid other than $0.9 \%$ saline (Enger et al., 1976) and the sodium load of a continuous infusion was considered to be too great, particularly for the smaller babies. In adults, percutaneous radial artery catheterisation has been found to be safe and reliable (Brown et al., 1969; Gardner et al., 1974), although cerebral embolism secondary to flushing of these catheters (Lowenstein et al., 1971), and necrosis of the skin of the forearm (Wyatt et al., 1974) have been described. 
These complications can probably be avoided by careful attention to quantity and speed of flushing. In spite of a high incidence of temporary radial artery thrombosis, necrosis of fingers or thumb appears to be rare (Downs et al., 1973; Bedford and Wollman, 1973) and can probably be prevented by first identifying the ulnar artery using transillumination, as it is said to be deficient in $6 \%$ to $12 \%$ of patients (Hollinshead, 1958, cited by Adams and Rudolph, 1975), and by careful performance of the Allen test (Allen, 1929). In contrast to the experience in adults, no major or irreversible complication has been seen in these babies.

The useful life of radial artery catheters has become progressively longer in this hospital. If the number of patients is divided chronologically into four approximately equal groups, the useful life of the catheter has been $38,59,89$, and 100 hours. This can partly be explained by improvements in the method. The size of the catheter has been reduced. The original catheter used was an Abbocath 20G which, because of its size, probably caused overdistension of the radial artery, particularly in the smaller babies, with intimal damage and subsequent thrombotic problems, although these were not seen clinically. Early in the series, a 3-way stopcock was attached directly to the end of the catheter. Removal of a sample inevitably caused movement of the catheter in the artery and further intimal damage and arterial spasm. Experience has also emphasised the importance of beginning withdrawal of the sample slowly to avoid sucking the wall of the artery on to the catheter tip; this often results in arterial spasm and failure to obtain a sample.

Once the flow has started, surprisingly high rates can be obtained (up to $10 \mathrm{ml}$ minute) and two babies have each received two exchange transfusions, withdrawing blood from the radial artery and injecting blood through an Abbocath in a peripheral vein. Radial artery catheters have also been used successfully to monitor the blood pressure continuously in some of these babies.

Percutaneous radial artery catheterisation is therefore a fairly easy technique using transillumination. Catheters so inserted can perform most of the functions demanded of an umbilical arterial catheter and have several advantages over other methods of obtaining arterial blood in sick babies.

I thank Professor H. K. A. Visser and Professor J. W. Scopes for advice; Dr J. W. Mettau, Dr R. Spritzer, Dr P. J. J. Sauer, Dr C. M. A. Bijleveld, and Dr W. P. F. Fetter for help in the development of this technique; and the nursing staff of the intensive care unit.

\section{References}

Adams, J. M., and Rudolph, A. J. (1975). The use of indwelling radial artery catheters in neonates. Pediatrics, 55, 261-265.

Allen, E. V. (1929). Thromboangiitis obliterans. Methods of diagnosis of chronic occulsive arterial lesions distal to the wrist with illustrative cases. American Journal of Medical Science, 178, 237-244.

Au-Yeung, Y. B., Sugg, V. M., Kantor, N. M., Chiu, T. T. W., and Garrison, R. D. (1977). Percutaneous catheterization of scalp arteries in sick infants. Journal of Pediatrics, 91, 106-108.

Bartlett, R. N., and Munster, A. M. (1968). An improved technique for prolonged arterial cannulation. New England Journal of Medicine, 279, 92-93.

Bedford, R. F., and Wollman, H. (1973). Complications of percutaneous radial-artery cannulation. Anesthesiology, 38, 228-236.

Brown, A. E., Sweeney, D. B., and Lumley, J. (1969). Percutaneous radial artery cannulation. Anaesthesia, 24, 532-536.

Bucci, G., Scalamandrè, A., Savignoni, P. G., Orzalesi, M., and Mendicini, M. (1966). Crib side sampling of blood from the radial artery. Pediatrics, 37, 497-498.

Cochran, W. D., Davis, H. T., and Smith, C. A. (1968). Advantages and complications of umbilical artery catheterization in the newborn. Pediatrics, 42, 769-777.

Dangman, B. C., Hegyi, T., Hiatt, M., Indyk, L., and James, L. S. (1976). The variability of $\mathrm{PO}_{2}$ in newborn infants in response to routine care (abstract). Pediatric Research, $10,422$.

Downs, J. B., Rackstein, A. D., Klein, E. F., Jr, and Hawkins, I. F., Jr (1973). Hazards of radial artery catheterization. Anesthesiology, 38, 283-286.

Egan, E. A., and Eitzman, D. V. (1971). Umbilical vessel catheterization. American Journal of Diseases of Children, 121, 213-218.

Enger, E., Jacobsson, B., and Sörensen, S. E. (1976). Tissue toxicity of intravenous solutions. A phlebographic and experimental study. Acta paediatrica Scandinavica, 65, 248-252.

Gardner, R. M., Schwartz, R., Wong, H. C., and Burke, I. P. (1974). Percutaneous indwelling radial-artery catheters for monitoring cardiovascular function. Prospective study of the risk of thrombosis and infection. New England Journal of Medicine, 290, 1227-1331.

Gauderer, M., and Holgersen, L. O. (1974). Peripheral arterial line insertion in neonates and infants: a simplified method of temporal artery cannulation. Journal of Pediatric Surgery, 9, 875-877.

Hoekstra, R. E., Semba, T., Fangman, J. L., and Strobel, J. L. (1977). Intestinal perforation following withdrawal of umbilical artery catheter. Journal of Pediatrics, 90, 290.

Knudsen, F. U., and Petersen, S. (1977). Neonatal septic osteoarthritis due to umbilical artery catheterisation. Acta paediatrica Scandinavica, 66, 225-227.

Krauss, A. N., Albert, R. F., and Kannan, M. M. (1970). Contamination of umbilical catheters in the newborn infant. Journal of Pediatrics, 77, 965-969.

Krishnamoorthy, K. S., Fernandez, R. J., Todres, I. D., and de Long, G. R. (1976). Paraplegia associated with umbilical artery catheterization in the newborn. Pediatrics, 58, 443-445.

Kuhns, L. R., Bednarek, F. J., Wyman, M. L., Roloff, D. W., and Borer, R. C. (1975). Diagnosis of pneumothorax or pneumomediastinum in the neonate by transillumination. Pediatrics, 56, 355-360. 
Lowe nstein, E., Little, J. W., and Lo, H. H. (1971). Prevention of cerebral embolization from flushing radial artery cannulas. New England Journal of Medicine, 285, 1414-1415.

McGovern, B. C., and Baker, A. R. (1968). Temporal artery catheterization for the monitoring of blood gases in infants. Surgical Gynecology and Obstetrics, 127, 601-602.

Malloy, M. H., and Nichols, M. M. (1977). False abdominal aortic aneurism: an unusual complication of umbilical arterial catheterization for exchange transfusion. Journal of Pediatrics, 90, 285-286.

Neal, W. A., Reynolds, J. W., Jarvis, C. W., and Williams, H. J. (1972). Umbilical artery catheterization: demonstration of arterial thrombosis by aortography. Pediatrics, $\mathbf{5 0}$, 6-13.

Pearse, R. G. (1977). Use of transillumination in percutaneous catheterisation of the radial artery in newborn babies (abstract). Archives of Disease in Childhood, 52, 821.

Plumer, L. B., Kaplan, G. W., and Mendoza, S. A. (1976). Hypertension in infants-a complication of umbilical arterial catheterization. Journal of Pediatrics, 89, 802-805.

Roberton, N. R. C., and Dahlenburg, G. W. (1969). Ductus arteriosus shunts in the respiratory distress syndrome. Pediatric Research, 3, 149-159.

Shaw, J. C. L. (1968). Arterial sampling from the radial artery in premature and full-term infants. Lancet, 2 , 389-390.

Thomsen, A. (1964). Arterial blood sampling in small infants. Acta paediatrica Scandinavica, 53, 237-240.

Todres, I. D., Rogers, M. C., Shannon, D. C., Moylan, F. H. B., and Ryan, J. F. (1975). Percutaneous catheterization of the radial artery in the critically ill neonate. Journal of Pediatrics, 87, 273-275.

Tooley, W. H. (1972). What is the risk of an umbilical artery catheter? Pediatrics, 50, 1-2.

Tyson, J. E., deSa, D. J., and Moore, S. (1976). Thromboatheromatous complications of umbilical arterial catheterization in the newborn period. Archives of Disease in Childhood, 51, 744-754.

Warley, M. A., and Gairdner, D. (1962). Respiratory distress syndrome of the newborn-principles in treatment. Archives of Disease in Childhood, 37, 455-465.

Wigger, H. J., Bransilver, B. R., and Blanc, W. A. (1970) Thromboses due to catheterization in infants and children. Journal of Pediatrics, 76, 1-11.

Wunderlich, B., and Reynolds, R. N. (1972). Arterial blood sampling in babies. American Journal of Diseases of Children, 123, 446-447.

Wyatt, R., Glaves, I., and Cooper, D. J. (1974). Proximal skin necrosis after radial artery cannulation. Lancet, 1 , 1135-1138.

Correspondence to Dr R. G. Pearse, Department of Paediatrics, Sophia Children's Hospital, Gordelweg 160, Rotterdam, The Netherlands.

Note added in proof: Since submitting this paper we have successfully catheterised the radial artery in a further 76 babies. There have been no complications. 